\title{
Sentinel lymph node biopsy in the setting of conjunctival melanoma: Report of two cases and literature review
}

\author{
Rodrigo Arrangoiz*, Jorge Sánchez-García, Fernando Cordera, David Caba, Eduardo Moreno, Efrain Cru1z, Enrique Luque-de-León and \\ Manuel Muñoz \\ Sociedad Quirúrgica S.C. at the American British Cowdray Medical Center. Department of Surgical Oncology and Head and Neck Tumors. Mexico City, Mexico
}

\begin{abstract}
Objective: To report two cases of conjunctival melanoma (CM) that underwent sentinel lymph mapping (SLNM) and sentinel lymph node biopsy (SLNB) with good results.

Introduction: Conjunctival melanoma $(\mathrm{CM})$ is a very rare malignancy, with an incidence of less than one per million cases per year. Metastatic dissemination may occur via lymphatic or hematogenous routes. The regional lymph nodes most commonly involved in the head and neck region are found in the deep cervical node chain and in the parotid gland. The management of the lymph nodes in patients with CM is debatable with some authors recommending SLNM with SLNB. The indications for performing SLNM and SLNB are CM with a thickness of $1 \mathrm{~mm}$ or greater.

Case report: Two patients diagnosed with CM underwent SLNM and SLNB with complete surgical resection of the conjunctival lesions and superficial parotidectomy as part of the SLNB. Final pathology reported confirmed a complete resection of the lesions and a negative SLNB. The procedure was performed without any postoperative complications. Both patients on follow-up are free of disease without evidence of local or regional recurrence.

Conclusion: Evidence of the accuracy SLNM and SLNB in CM in the literature is sparse. We report on two cases where the identification of the SLN was accurate with no postoperative complications. We believe based the available evidence that SLNM and SNLB is feasible, accurate, with a low complication rate in patient with CM.
\end{abstract}

\section{Introduction}

Conjunctival melanoma $(\mathrm{CM})$ is a rare malignancy with an incidence of 0.15 to 0.49 cases per million persons per year [1,2]. It is a very aggressive non-cutaneous neoplasm that represents only $5 \%$ of ocular melanomas with a 10 -year mortality rate of $30 \%[3,4]$. It is identified more frequently in the elderly population (53\% of the cases), and in Caucasians ( $94 \%$ of the cases) [5]. The main clinical manifestations are a pigmented lesion, lump, or swelling in the conjunctiva in $83 \%$ of the cases. In approximately $61 \%$ of the cases the lesion is usually located at the limbal conjunctiva and in $46 \%$ of the cases in the temporal quadrant of the eye [5]. Metastases can be detected with positron emission tomography / computed tomography (PET/CT). However, micro-metastasis through the lymphatic system can only be detected with sentinel lymph node mapping (SLNM) and sentinel lymph node biopsy (SLNB) [6]. The aim of this study is to present two cases of CM were SLNM and SLNB was performed as part of their management with adequate identification of the SLN with no added morbidity.

\section{Case 1}

A 72-year old male, with a history of chronic irritation of the left eye for more than two months, was evaluated by an ophthalmologist who diagnosed a CM and send him to our clinic. We identified two pigmented lesions, one of approximately $1 \mathrm{~cm}$ in size and another of approximately $2 \mathrm{~cm}$ in size. Both lesions had irregular borders, one was in the temporal region, and the other on the nasal region of the eye (Figure 1). He was initially treated with Mitomycin C for 16 days without any objective response. After a multidisciplinary review of the case, it was decided to recommend complete resection with SLNM and SLNB. The ophthalmology-oncology team performed the resection and the head and neck team, performed the SLNM and SLNB which included a superficial parotidectomy with identification and preservation of the facial nerve (Figure 2). The final pathology report showed melanocytic hyperplasia with atypia and a conjunctival sub-epithelial nevus that was completely resected (R0) and the SLNB was negative. Currently, the patient is free of disease without evidence of recurrence.

\section{Case 2}

A 44-year old female, with a three-week history of a pigmented lesion on the conjunctiva of the left eye. An ophthalmologist initially managed the pigmented lesion with topical treatment without response, followed by an excisional biopsy. The pathology report showed a CM of less than $1.5 \mathrm{~cm}$ in size with microscopically residual tumor (pT1B, cN0, cM0) (Figure 3). After presenting the case in our multidisciplinary tumor board, it was decided to perform a wide local excision with SLNM and SLNB. The ophthalmology-oncology team

Correspondence to: Rodrigo Arrangoiz, Sociedad Quirúrgica S.C. at the American British Cowdray Medical Center. Department of Surgical Oncology and Head and Neck Tumors. Av. Carlos Graef Fernandez \# 154 - 515 Colonia Tlaxala, Delegación Cuajimalpa Mexico City, Mexico 05300, Tel: 52551664 7200; E-mail: rodrigo.arrangoiz@yahoo.com

Key words: conjunctival melanoma, sentinel lymph node biopsy, sentinel lymph node mapping, superficial parotidectomy

Received: May 15, 2017; Accepted: June 23, 2017; Published: June 26, 2017 


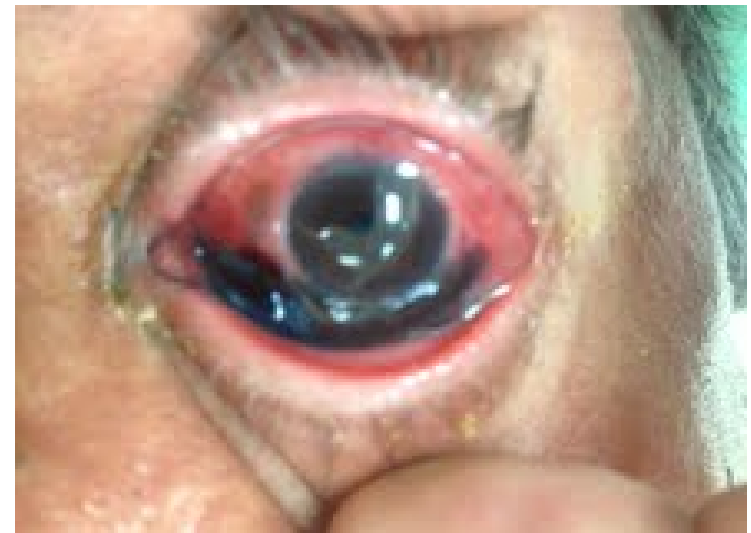

Figure 1. Pigmented lesion of the limbal conjunctiva of the left eye.

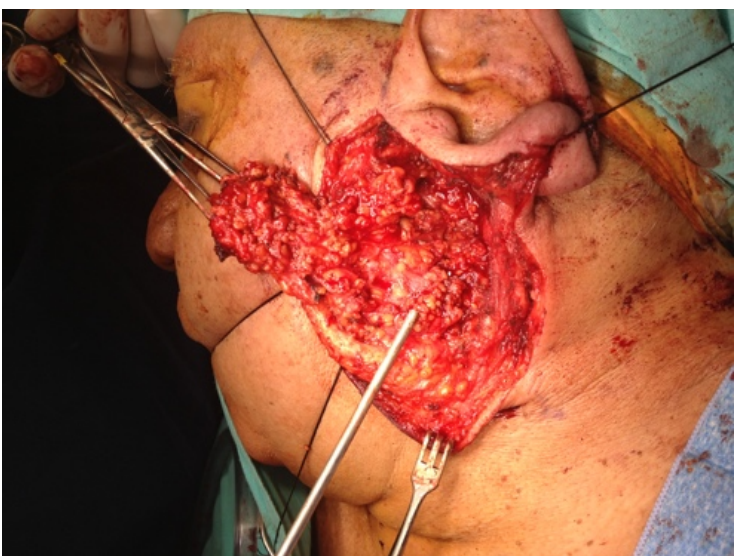

Figure 2. Superficial parotidectomy with preservation of the facial nerve.

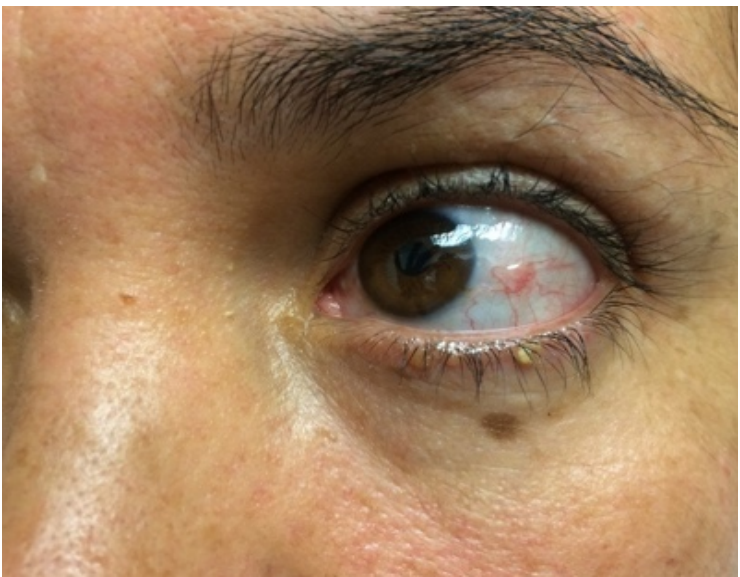

Figure 3. Pigmented lesion of limbal conjunctiva of the left eye.

performed the excision and the head and neck team performed the SLNM and SLNB which included a superficial parotidectomy with identification and preservation of the facial nerve (Figure 4). The final pathology report showed a complete resection with negative margins and the SLNB was negative. Currently she is free of disease without evidence of recurrence.

\section{Discussion}

$\mathrm{CM}$ is a very rare malignancy with an incidence of 0.15 to 0.49 per million of persons (0.15 in Asians, 0.18 in Blacks, 0.17 in American
Indians, 0.33 in Hispanics and 0.49 in non-Hispanic Whites) [1]. Approximately $1 \%$ of all CM cases occur in Hispanics. The mean age at diagnosis is 67.2 years and doesn't have a gender predilection [5,7]. CM typically presents as a pigmented nodular or flat conjunctival lesion $[6,8]$. CMs usually originate from atypical melanocytes in the epithelial basal layer [8], but they may arise from primary acquired melanosis ( $53 \%$ to $59 \%$ of the cases), from a pigmented nevus ( $4 \%$ of the cases), and de novo ( $26 \%$ to $37 \%$ of the cases). Those arising de novo have the worse prognosis [9].

Tumor thickness greater than $2 \mathrm{~mm}$ [3], histologic evidence of ulceration and mitotic figure count greater than $1 / \mathrm{mm}^{2}$ have been correlated with regional lymph node metastasis [10]. CMs display tumor-associated lymphatic vasculature within and around the tumor, inducing lymphangiogenesis. The CM-associated lymphangiogenesis is associated with an increased risk of local recurrence, lymphatic spread, distant metastasis, and CM-related death [11]. The usual sites of metastasis are the regional lymph nodes in $15 \%$ to $60 \%$ of the cases, mainly in the intra-parotid and submandibular nodes $[12,13]$.

Esmaeli et al. [14], where the first to report on SLNM and SLNB in CM, since then numerous reports of SLNM and SLNB have been published in the literature by various authors [4,6,15-20]. In the last decade SLNM and SLNB for CM has evolved dramatically because it has been shown to detect regional lymph node spread with great accuracy and minimal morbidity [13,20]. The positivity SLNB rate ranges from $11 \%$ to $20 \%[13,21]$, with a false negativity rate of $8 \%$ [13]. Most of the data regarding SLNM and SLNB in CM come from small case series due to the rarity of this tumor, and controlled trials with uniform techniques are required to validate it use in CM.

We performed a similar technique of SLNM and SLNB as reported by Esmaeli et al [14]. Lymphoscintigraphy was performed approximately two hours before the operation, a local aesthetic was applied on the conjunctival surface, then 0.3 to $0.4 \mathrm{mCi}$ of technetium 99-sulfur colloid in $0.2 \mathrm{~mL}$ normal saline was injected sub-conjunctively near the tumor. Single photon emission computed tomography was performed to help identify the lymphatic drainage of the eye. Intraoperatively, we injected $0.2 \mathrm{ml}$ of patent blue dye and with a handheld gamma probe we identified the SLNs trans-cutaneously. The nodes that were radioactive and blue were removed until the nodal basin count was less than twice the background level $[13,19]$. Earlier studies identified that blue dye combined with radiolabeled sulfur colloid enhances the detection rate of SLNs. In our cases, the SLNs were in the parotid gland, and one of the complications of SLNB in the parotid area is damage to the facial nerve and/or its branches, which did not occur with our patients.

\section{Conclusion}

In summary, SLNM and SLNB in CM is a feasible technique with minimal morbidity, that can be performed by surgeons with experience

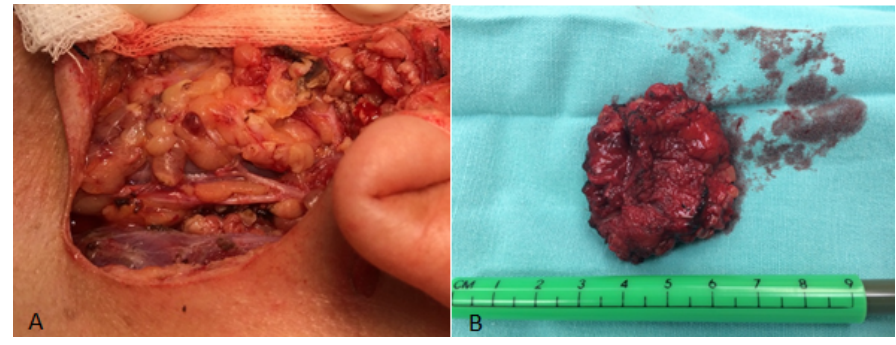

Figure 4. Superficial parotidectomy with preservation of the facial nerve (A). Surgical piece of parotidectomy (B). 
in SNLM. We are reporting on two cases of CM that SLNM and SLNB where performed with good accuracy and with no long-term complications.

\section{References}

1. Hu DN, Yu G, McCormick SA, Finger PT (2008) Population-Based Incidence of Conjunctival Melanoma in Various Races and Ethnic Groups and Comparison with Other Melanomas. Am J Ophthalmol 145: 418-423. [Crossref]

2. Larsen AC (2016) Conjunctival malignant melanoma in Denmark. Epidemiology, treatment and prognosis with special emphasis on tumorigenesis and genetic profile. Acta Ophthalmol 94: 842. [Crossref]

3. Brownstein S (2004) Malignant melanoma of the conjunctiva. Cancer Control 11: 310316. [Crossref]

4. Zoroquiain P, Nayman T, Fernandes B, Burnier MN (2016) Conjunctival Melanoma With Morphologic Diversity and Orbital Invasion. Am J Dermatopathol 38: e52-e56. [Crossref]

5. Shields CL, Alset AE, Boal NS, Casey MG, Knapp AN, et al. (2017) Conjunctival Tumors in 5002 Cases. Comparative Analysis of Benign Versus Malignant Counterparts. The 2016 James D. Allen Lecture. Am J Ophthalmol 173: 106-133. [Crossref]

6. Vora GK, Demirci H, Marr B, Mruthyunjaya P (2017) Advances in the management of conjunctival melanoma. Surv Ophthalmol 62: 26-42. [Crossref]

7. Larsen AC, Dahmcke CM, Dahl C, Siersma VD, Toft PB, et al. (2015) A Retrospective Review of Conjunctival Melanoma Presentation, Treatment, and Outcome and an Investigation of Features Associated With BRAF Mutations. JAMA Ophthalmol 133:1295-1303. [Crossref]

8. Jovanovic P, Mihajlovic M, Djordjevic-Jocic J, Vlajkovic S, Cekic S, et al. (2013) Ocular melanoma: an overview of the current status. Int J Clin Exp Pathol 6: 12301244. [Crossref]

9. Shields CL, Markowitz JS, Belinsky I, Schwartzstein H, George NS, et al. (2011) Conjunctival melanoma: outcomes based on tumor origin in 382 consecutive cases. Ophthalmology 118: 389-395. [Crossref]
10. Bita Esmaeli, Merrick Ross, Melissa Fellman, Hilda Cruz, Kim SK (2012) Histologic features of conjunctival melanoma predictive of metastasis and death (an American Ophthalmological thesis). Trans Am Ophthalmol Soc 110: 64-73.

11. Briceño CA, Elner VM, Demirci H (2016) Lymphangiogenic and Chemotactic Factors in Conjunctival Melanoma. Ophthal Plast Reconstr Surg 32: 428-433. [Crossref]

12. Wainstein AJ, Drummond-Lage AP, Kansaon MJ, Bretas GO, Almeida RF, et al. (2014) Sentinel lymph node biopsy for conjunctival malignant melanoma: surgical techniques. Clin Ophthalmol 9: 1-6. [Crossref]

13. Mendoza PR, Grossniklaus HE (2015) Sentinel lymph node biopsy for eyelid and conjunctival tumors: what is the evidence? Int Ophthalmol Clin 55: 123-136. [Crossref]

14. Esmaeli B, Eicher S, Popp J, Delpassand E, Prieto VG, et al. (2001) Sentinel lymph node biopsy for conjunctival melanoma. Ophthal Plast Reconstr Surg 17:436-442. [Crossref]

15. Aziz HA, Gastman BR, Singh AD (2015) Management of Conjunctival Melanoma: Critical Assessment of Sentinel Lymph Node Biopsy. Ocul Oncol Pathol 1: 266-273.

16. Fabian ID, Thaung C, Cohen VML (2017) A conjunctival and choroidal melanoma in the same eye: report of two cases. Graefes Arch Clin Exp Ophthalmol 255: 841-842. [Crossref]

17. Maleka A, Åström G, Byström P, Ullenhag GJ (2016) A case report of a patient with metastatic ocular melanoma who experienced a response to treatment with the BRAF inhibitor vemurafenib. BMC Cancer [Crossref].

18. Nalcaci S, Palamar M, Yaman B, Akalin T, Mentes J (2016) Choroidal malignant melanoma with no extraocular extension presenting as orbital cellulitis. Orbit 35: 285-287.

19. Savar A, Ross MI, Prieto VG, Ivan D, Kim S, et al. (2009) Sentinel lymph node biopsy for ocular adnexal melanoma: experience in 30 patients. Ophthalmology 116: 2217 2223. [Crossref]

20. Cohen VM, Tsimpida M, Hungerford JL, Jan H, Cerio R, et al. (2013) Prospective study of sentinel lymph node biopsy for conjunctival melanoma. Br J Ophthalmol 97 1525-1529. [Crossref]

21. Pfeiffer ML, Ozgur OK, Myers JN, Peng A, Ning J, et al. (2017) Sentinel lymph node biopsy for ocular adnexal melanoma. Acta Ophthalmol 95: e323-e328. [Crossref]

Copyright: (C2017 Arrangoiz R. This is an open-access article distributed under the terms of the Creative Commons Attribution License, which permits unrestricted use, distribution, and reproduction in any medium, provided the original author and source are credited. 